\title{
FITOSSANIDADE
}

\section{FREQUENNCIA DE BACILLUS SPP. EM SOLOS DE DIFERENTES SISTEMAS DE CULTIVO DE ARROZ IRRIGADO EM CACHOEIRINHA, RS ( $\left.{ }^{\mathbf{1}}\right)$}

\author{
LEILA LUCIA FRITZ $\left({ }^{2 *}\right)$; DIOUNEIA LISIANE BERLITZ $\left({ }^{2}\right)$; VERA REGINA MUSSOI MACEDO $\left({ }^{3}\right)$; \\ VILMAR MACHADO $\left({ }^{4}\right)$; LIDIA MARIANA FIUZA ${ }^{(2,3)}$
}

\begin{abstract}
RESUMO
Bacilos entomopatogênicos são bactérias observadas principalmente no solo, consideradas importantes agentes no controle biológico de doenças e pragas da agricultura. No entanto, existem poucos estudos que relatam a influência das práticas agrícolas nas populações de Bacillus spp. Essa pesquisa objetivou avaliar a freqüência de bactérias entomopatogênicas pertencentes ao gênero Bacillus obtidas de amostras de solo coletadas no ano agrícola de 2006/2007 de diferentes sistemas de cultivo de arroz irrigado da EEA-IRGA, Cachoeirinha (RS). Foram analisadas 36 amostras de solos, oriundas de três sistemas de plantio de arroz irrigado, pré-germinado (SPG), convencional (SPC), plantio direto (SPD) e de uma área sem plantio de arroz (C). Para tanto, um grama de solo foi diluído, pasteurizado e inoculado em Ágar Nutriente (AN), incubado a $30^{\circ} \mathrm{C}$, por 24 horas. Todas as unidades formadoras de colônias bacterianas (UFC) foram repicadas em meios seletivos e as espécies, B. thuringiensis, B. sphaericus e B. cereus, foram identificadas por microscopia de contraste de fase. Os resultados revelaram que não houve diferença significativa entre os sistemas de plantio analisados. Por outro lado, a frequência de Bacillus spp. variou entre as diferentes fases do plantio de arroz nos períodos amostrados. A irrigação foi o principal fator que contribuiu para a variação da frequência dos Bacillus em sistemas de plantio de arroz irrigado da EEA-IRGA.
\end{abstract}

Palavras-chave: agroecossistemas, bacilos entomopatogênicos, sistemas de plantio, Bacillus thuringiensis, Bacillus sphaericus, Bacillus cereus.

$\left({ }^{1}\right)$ Recebido para publicação em 28 de novembro de 2008 e aceito em 9 de novembro de 2009.

$\left({ }^{2}\right)$ Universidade do Vale do Rio dos Sinos, Microbiologia, Ciências da Saúde, Caixa Postal 275, 93001-970 São Leopoldo (RS). E-mail: leilafritz@gmail.com $\left(^{*}\right)$ Autora correspondente.

$\left({ }^{3}\right)$ Instituto Riograndense do Arroz, Estação Experimental do Arroz, Av. Bonifácio Carvalhos Bernardes, 94930-030 Cachoeirinha (RS). E-mail: vera-macedo@irga.rs.gov.br; fiuza@unisinos.br.

$\left({ }^{4}\right)$ Universidade de Caxias do Sul, Biologia, Rua Francisco Getúlio Vargas, 1130, Caixa Postal 1352, 95001-970, Caxias do Sul (RS). E-mail: vmachado27@hotmail.com. 


\title{
ABSTRACT \\ FREQUENCY OF BACILLUS SPP. IN THE SOILS OF SEVERAL DIFFERENT IRRIGATED RICE CULTIVATION SYSTEMS, IN CACHOEIRINHA, RS
}

\begin{abstract}
Entomopathogenic Bacillus are bacteria found mainly in the soil and are considered important agents in biological control of agricultural diseases and pests. However, there are fen studies describing the influence that different agricultural practices have on Bacillus spp. populations. This study proposes to determine the occurrence frequency of entomopathogenic bacteria from Bacillus genus in soil samples. These were collected during the agricultural year 2006/07 from different irrigated rice cultivation systems used in the EEA-IRGA plantations in Cachoerinha, State of Rio Grande do Sul, Brazil. We analyzed 36 soil samples taken from three irrigated rice plantation systems; (i) Pre-germinated (SPG); (ii) Conventional (SPC); and (iii) Direct plantation (SPD) and a fourth sample from a non-planted area (C). In each test one gram of soil was diluted, pasteurized and inoculated in Nutrient Agar (NA) and incubated for 24 hours at $30^{\circ} \mathrm{C}$. All the bacteria colony-forming units (CFU) were transplanted to selective mediums and the $B$. thuringiensis, B. sphaericus and B. cereus species were identified using a phase contrast microscope. No significant differences in the occurrence frequencies were found in the soil samples of all plantation systems analyzed. On the other hand, the Bacillus spp frequency varied in the sampled period during the different growing phases of the irrigated rice in the EEA-IRGA plantations evaluated. Irrigation was the main factor contributing to variation of the Bacillus in the plantations.
\end{abstract}

Key words: agroecosystems, entomopathogenic bacillus, cultivation systems, Bacillus thuringiensis, Bacillus sphaericus, Bacillus cereus.

\section{INTRODUÇÃO}

O arroz (Oryza sativa L.) é considerado o principal alimento para grande parte da população mundial, constituindo-se em um dos cereais mais produzidos no mundo juntamente com o trigo e o milho. O Estado do Rio Grande do Sul é responsável por $50 \%$ da produção brasileira de arroz, demonstrando a grande importância dessa cultura para o Estado (AgostinetTo et al., 2001; MARCHEZAN et al., 2004; SOARES et al., 2005).

Dentre os cultivos de arroz, o irrigado pode ser cultivado sob diferentes formas, como os sistemas pré-germinado (SPG), convencional (SC) e de plantio direto (SPD) (BoHNEN et al., 2005). O sistema prégerminado ocupa aproximadamente $11 \%$ das áreas destinadas à cultura no Rio Grande do Sul. Essa forma de cultivo preconiza a semeadura sobre a lâmina de água com posterior drenagem para melhor estabelecimento das plântulas (MARCHEZAN et al., 2001; MARChEZAN et al., 2004). No sistema de plantio direto, os resíduos culturais permanecem na superfície, onde é feito apenas um sulco para a semeadura, garantindo menor rendimento do solo (Neto et al., 2006; Souza et al., 1995). Já o sistema convencional é caracterizado pela incorporação total dos resíduos vegetais do cultivo anterior no solo e entrada de água somente 20 a 40 dias após a semeadura, deixando sua superfície desprotegida até o estabelecimento da próxima cultura (BONHEN et al., 2005; PfüLLER et al., 2000).

Apesar da utilização contínua do solo para as práticas agrícolas, o mesmo pode ser rico do ponto de vista biológico uma vez que muitos microrganismos encontrados nesse ambiente são considerados importantes no controle biológico de doenças e pragas da agricultura (Azevedo, 1998). Dentre os microrganismos do solo, os bacilos entomopatogênicos têm especial importância, uma vez que suas células, em forma de bastonete, possuem ampla capacidade de produzir endósporos e toxinas, que os tornam importantes no controle de pragas agrícolas (HABIB e ANDRADE, 1998; Dias et al., 1999).

Dentre esses bacilos, B. thuringiensis é a espécie de maior importância no controle de pragas agrícolas. É uma bactéria Gram-positiva, aeróbica ou anaeróbica facultativa, caracterizandose pela produção de corpos paraesporais, denominados cristais (Ввовоwsку et al., 2003) que são formados por diferentes polipeptídios, conhecidos como proteínas Cry, com atividade inseticida a diversas ordens de insetos, além de nematóides, protozoários e ácaros (CAPALBo et al., 2005; Gill et al., 1995). O entomopatógeno B. sphaericus também é Gram-positivo, constatado com frequência no solo, porém suas células vegetativas possuem como principal característica a presença de esporos esféricos que deformam o esporângio, e isso lhe confere o aspecto de raquete (SILva et al., 2002). Já B. cereus com esporos cilíndricos e elípticos, geralmente em posição central, é considerada não-cristalífera, embora possa causar virulência e patogenicidade em espécies de insetos cujo líquido intersticial médio tenha $\mathrm{pH}$ entre 6,6 e 7,4 (Habib e Andrade, 1998). 
As transformações microbianas que se observam no solo por conta das diferentes populações que nele ocorrem, bem como suas distintas reações químicas, podem ser alteradas sempre que houver no ecossistema algum tipo de interferência. Assim, na aplicação de diversos tipos de manejo, podem existir diferentes disponibilidades de substratos que determinarão o favorecimento ou a inibição do estabelecimento dos diferentes grupos microbianos (CAstro e PADro, 1993).

As espécies de Bacilllus citadas podem ser utilizadas no controle natural de pragas das lavouras, uma vez que são entomopatógenos com propriedades inseticidas, tornando-se um método alternativo ao uso de inseticidas químicos. Dessa forma, este trabalho teve como objetivo avaliar a variação na frequência de bactérias entomopatogênicas pertencentes ao gênero Bacillus, obtidas de amostras de solo coletadas em diferentes sistemas de plantio de arroz irrigado do Rio Grande do Sul, em diferentes etapas da cultura.

\section{MATERIAL E MÉTODOS}

\section{1 Área de estudo}

O estudo foi realizado em Cachoeirinha, no Rio Grande do Sul ( $29^{\circ} 55^{\prime} 30^{\prime \prime}$, S; $\left.50^{\circ} 58^{\prime} 21^{\prime \prime} \mathrm{W}\right)$, região orizícola da planície costeira, sendo a fonte de irrigação da cultura proveniente do rio Gravataí. A cultivar utilizada na realização dos experimentos foi IRGA 422CL, que se caracteriza por ser de ciclo longo, como maior massa de grão, tolerante ao herbicida Only (Imazetopir) e ter como principal característica o controle de infestações de arroz vermelho.

As amostras de solo foram coletadas nos três sistemas de cultivo de arroz irrigado citados: prégerminado (SPG), convencional (SPC) e plantio direto (SPD), e de uma área controle (C), sem plantio de arroz irrigado por aproximadamente 12 anos, totalizando quatro tratamentos (SPG, SPC, SPD e C) e três repetições. A área de estudo foi composta por 12 subáreas de $1.120 \mathrm{~m}^{2}$, totalizando $13.440 \mathrm{~m}^{2}$. Cada subárea foi interiormente dividida em dez parcelas de $112 \mathrm{~m}^{2}$ para a aleatoriedade das coletas de solos, e os sistemas de plantio foram separados entre si por taipas de dois metros de distância para evitar o contato entre eles (Figura 1). A preparação das subáreas foi realizada com o auxílio da equipe do IRGA (2005), conforme as Recomendações Técnicas da Pesquisa do Sul do Brasil, para o ciclo da cultura do arroz irrigado.

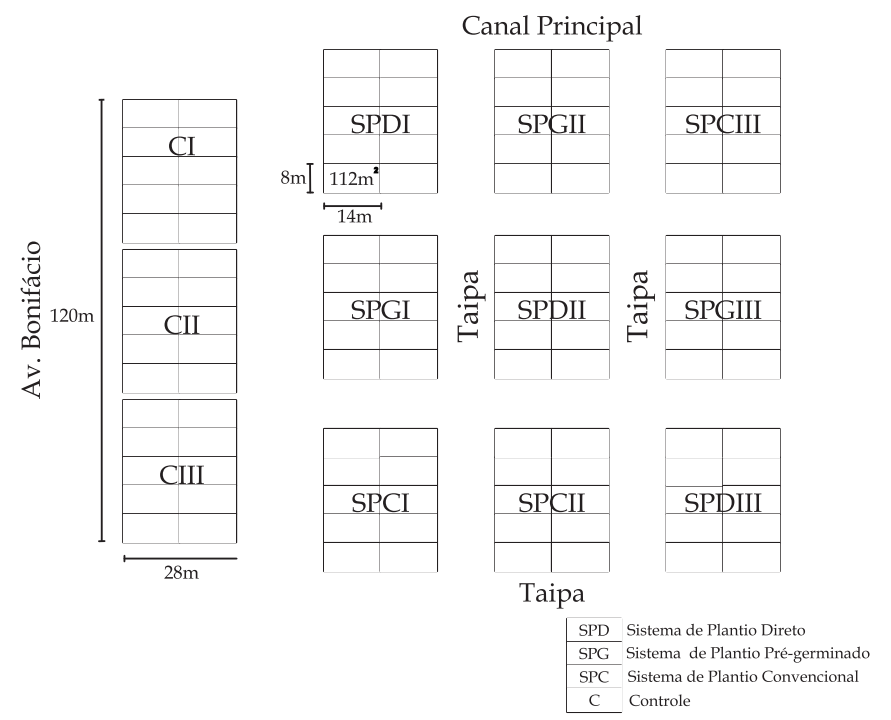

Figura 1. Delineamento experimental da área de estudo e respectivos tratamentos de culturas de arroz irrigado. Cachoeirinha (RS) 2006/07

\subsection{Coletas de solo}

As coletas ocorreram no período que compreende o ciclo do arroz irrigado no ano agrícola 2006/2007 e foram efetuadas em três épocas: antes do preparo do solo em setembro de 2006 (1. ${ }^{\text {a }}$ coleta); após a irrigação e aplicação de fertilizantes, em novembro de 2006 (2. ${ }^{a}$ coleta) e posterior à colheita, em março de 2007 (3. ${ }^{a}$ coleta). Em cada período e subárea, foram coletadas dez amostras de solo com o auxílio de um trado, e cada amostra corresponde a uma camada de $15 \mathrm{~cm}$ de espessura de solo. As amostras pertencentes à mesma repetição e subárea foram homogeneizadas, tendo sido retirada uma amostra composta para cada subárea, em um total de 36 amostras de solo. Posteriormente, foram acondicionadas em sacos plásticos identificados (padrão IRGA), mantidas na estufa para secagem a uma temperatura de $40{ }^{\circ} \mathrm{C}$, moídas, peneiradas em malha padrão $(200 \mathrm{~mm})$ e encaminhadas para o Laboratório de Microbiologia da Unisinos para o isolamento de Bacillus spp.

\subsection{Isolamento bacteriano}

$\mathrm{O}$ isolamento das bactérias pertencentes ao gênero Bacillus seguiu a metodologia descrita pela WoRLD OrganizATION (1985). Para tanto, um grama de solo foi diluído em $10 \mathrm{~mL}$ de solução salina estéril $(0,01 \mathrm{mM}$ $\mathrm{CaCo}_{3} 7 \mathrm{H}_{2} \mathrm{O} ; 0,08 \mathrm{mM} \mathrm{MgSo}{ }_{4} \cdot 7 \mathrm{H}_{2} \mathrm{O} ; 0,006 \mathrm{mM}$ $\mathrm{FeSO}_{4} \cdot 7 \mathrm{H}_{2} \mathrm{O} ; 0,07 \mathrm{mM} \mathrm{MnSO}$. $7 \mathrm{H}_{2} \mathrm{O} ; 0,006 \mathrm{mM}$ $\left.\mathrm{ZnSO}_{4} .7 \mathrm{H}_{2} \mathrm{O} ; \mathrm{pH} 7,0\right)$ e homogeneizado no vórtex por um minuto. Foi retirada uma alíquota de $1000 \mu \mathrm{L}$ para o processo de pasteurização $\left(12\right.$ minutos a $80^{\circ} \mathrm{Ce} 5$ minutos a $4{ }^{\circ} \mathrm{C}$ ), visando à seleção das bactérias esporulantes. 
Após esse período, $500 \mu \mathrm{L}$ da suspensão foi diluída em $4,5 \mathrm{~mL}$ de solução salina. A solução resultante foi homogeneizada no vórtex, e dela foi diluída uma alíquota de $500 \mu \mathrm{L}$ em outros $4,5 \mathrm{~mL}$ da mesma solução salina, atingindo uma proporção de 1/100. Dessa última, foram aplicados $100 \mu \mathrm{L}$ em placa de Petri contendo Ágar Nutriente, a qual foi incubada em estufa a $30{ }^{\circ} \mathrm{C}$ durante 24 horas. As colônias crescidas individualmente no meio foram quantificadas com o auxílio de um contador de colônias e analisadas morfologicamente através de um estereomicroscópio $(40 \times)$.

Os inóculos foram acondicionados com auxílio de palitos seletivos, contendo Meio Usual Glicosado e antibióticos (Penicilina-G e Estreptomicina) e, posteriormente, submetidos a incubador rotativo a $30^{\circ} \mathrm{C}, 180 \mathrm{rpm}$ durante 24 horas. As culturas bacterianas que tiveram crescimento positivo em um dos antibióticos citados foram analisadas em microscopia de contraste de fase $(1000 \times)$, objetivando identificar a presença de $B$. thuringiensis $(B t), B$. cereus $(B c)$ e B. sphaericus $(B s)$.

\subsection{Análises estatísticas}

Para comparar as diferenças observadas na frequência das espécies de Bacillus spp. entre os diferentes tipos de plantio em cada fase da cultura do arroz, foi utilizado o $\chi^{2}$, ou teste de permutação exata (Rolf e Bentzen, 1989) com mil randomizações. Esse teste é útil quando os valores esperados são muito pequenos, como é o caso das frequências de Bacillus observadas em determinadas etapas do presente estudo.

\section{RESULTADOS E DISCUSSÃO}

No solo de arroz irrigado foram obtidas bactérias esporulantes, das quais, 336 pertenciam ao gênero Bacillus spp.. Dentre essas, 35,42\% foram identificadas como $B$. thuringiensis, $16,96 \%$ como $B$. cereus, $9,52 \%$ como B. sphaericus e $38,10 \%$ como Bacillus sp.. Travers et al., (1987) selecionaram bactérias de amostras de solos, e verificaram que, entre 20 e $96 \%$ eram espécies formadoras de cristal pertencentes ao gênero Bacillus, incluindo B. thuringiensis e B. sphaericus. Da mesma forma, PolANCZYK et al. (2004) ao isolarem microrganismos de solos orizícolas, encontraram 772 colônias bacterianas, das quais $50,27 \%$ eram isolados de Bacillus. Dentre estas, 79,0\% foram identificados como $B$. thuringiensis e $21,0 \%$ como $B$. cereus.

CHIN et al. (1999) sugerem que as bactérias do gênero Bacillus ocorrem frequentemente em solos de arrozais e que Bacillus spp. são partes numericamente importantes da comunidade microbiana do solo. Esses mesmos autores associam a ampla ocorrência de $B$. thuringiensis em ambientes terrestres, em relação às demais espécies, devido à sua capacidade de sobrevivência em condições adversas e ao fácil transporte pelo vento, chuva e animais.

Já DiAs et al. (1999), isolaram Bacillus spp. de diferentes áreas da Argentina, inclusive de solos agrícolas, e obtiveram uma frequência de B. sphaericus maior $(2,1 \%)$ em relação a $B$. thuringiensis (1,6\%). No entanto, SiLva et al. (2002) obtiveram uma maior porcentagem de $B$. thuringiensis $(9,1 \%)$ em relação a $B$. sphaericus $(5,1 \%)$ em diferentes amostras de solos oriundas de todas as regiões brasileiras (cultivadas e não cultivadas).

As análises estatísticas revelaram que não houve diferença significativa nas quantidades de Bacillus spp. isoladas em cada sistema de cultivo (SPG, $\mathrm{SPC}, \mathrm{SPD})$ em cada fase da cultura $(\mathrm{p}>0,05)$. Devido ao fato de as análises não serem consideradas significativas, para comparar a variação de Bacillus spp. entre as fases, foram utilizadas as frequências totais das bactérias em cada fase da cultura nos sistemas de plantio. Os dados das espécies de Bacillus, nos diferentes sistemas de plantio em suas respectivas fases, estão indicados nas tabelas 1, 2 e 3.

Os resultados estão de acordo com os estudos realizados por PFülLER et al. (2000), que analisaram a frequência de microrganismos em diferentes sistemas de plantio. Esses autores relataram que a população microbiana não diferiu significativamente entre os sistemas de plantio, verificando-se maior população microbiana no SPC com $986,31 \times 10^{4}$ propágulos de microrganismos $\mathrm{g}^{-1}$ de solo seco e o SPD com $943,89 \times 10^{4}$ propágulos de microrganismos/ $\mathrm{g}^{-1}$ de solo seco. O mesmo resultado foi observado nos experimentos realizados por CASTRO e PRADO (1993), nos quais foi constatada uma ordem de grandeza próxima a $10^{7}$ bactérias/grama de solo, independentemente do tipo de manejo aplicado.

Tratando-se das três fases da cultura do arroz irrigado, os resultados revelaram que houve diferença significativa nas espécies de Bacillus spp. nas fases de plantio do arroz $(p<0,01)$ (Figura 2$)$, embora o número de colônias bacterianas não tenha variado significativamente entre cada fase da cultura $\left(\chi^{2}=2.036\right.$, $\mathrm{gl}=2, \mathrm{p}>0,05)$. Nos experimentos realizados por PFüLLER et al. (2000) houve variações no número de microrganismos entre as épocas de coleta do solo. Esses autores mencionam que na primeira coleta apresentou um maior número de microrganismos em relação à segunda e sugerem que isso pode ser explicado pelo estágio de desenvolvimento das culturas de cobertura do solo (florescimento), desenvolvimento que promove uma menor oscilação térmica do solo e maior efeito rizósférico nas populações. 
Tabela 1. Frequência de isolados de Bacillus spp. em solos de sistemas de plantio antes do preparo do solo, em cultura do arroz irrigado. Cachoeirinha (RS)

\begin{tabular}{|c|c|c|c|c|c|}
\hline Tratamento & B. thuringiensis & B. cereus & B. sphaericus & Bacillus sp. & Bacillus spp. \\
\hline SPD & 12 & 3 & 4 & 3 & 22 \\
\hline SPG & 4 & 0 & 1 & 12 & 17 \\
\hline SPC & 10 & 0 & 1 & 15 & 26 \\
\hline Total & 26 & 3 & 6 & 30 & 65 \\
\hline
\end{tabular}

$\mathrm{SPD}=$ sistema de plantio direto. SPG = sistema de plantio germinado. SPC = sistema de plantio convencional.

Tabela 2. Frequência de isolados de Bacillus spp. em solos de cultivo de arroz irrigado em diferentes sistemas de plantio após a irrigação da cultura. Cachoeirinha (RS)

\begin{tabular}{|c|c|c|c|c|c|}
\hline Tratamento & B. thuringiensis & B. cereus & B. sphaericus & Bacillus sp. & Bacillus spp. \\
\hline SPD & 4 & 7 & 5 & 5 & 21 \\
\hline SPG & 8 & 11 & 1 & 14 & 34 \\
\hline SPC & 9 & 11 & 0 & 15 & 35 \\
\hline Total & 21 & 29 & 6 & 34 & 90 \\
\hline
\end{tabular}

$\mathrm{SPD}=$ sistema de plantio direto. SPG = sistema de plantio germinado. SPC = sistema de plantio convencional.

Tabela 3. Frequência de isolados de Bacillus spp. em solos de cultivo de arroz irrigado em diferentes sistemas de plantio após a colheita da cultura. Cachoeirinha (RS)

\begin{tabular}{lccccc}
\hline Tratamento & B. thuringiensis & B. cereus & B. sphaericus & Bacillus sp. & Bacillus spp. \\
\hline SPD & 18 & 1 & 1 & 11 & 31 \\
SPG & 7 & 9 & 0 & 13 & 29 \\
SPC & 17 & 6 & 2 & 12 & 36 \\
\hline Total & 42 & 16 & 2 & 36 & 96 \\
\hline
\end{tabular}

$\mathrm{SPD}=$ sistema de plantio direto. $\mathrm{SPG}=$ sistema de plantio germinado. $\mathrm{SPC}=$ sistema de plantio convencional.

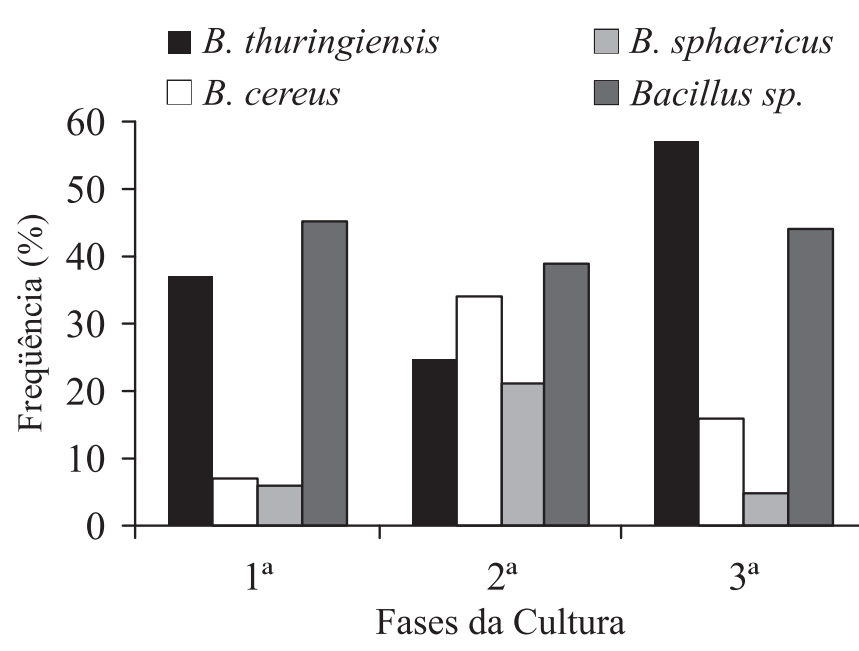

Figura 2. Freqüência de Bacillus spp. em amostras de solos orizícolas em amostragens anterior ao preparo do solo $\left(1{ }^{a}\right)$, após a irrigação $\left(2 .^{a}\right)$ e após a colheita do arroz (3. $\left.{ }^{\mathrm{a}}\right)$ Cachoeirinha (RS)
No presente trabalho, em $B$. thuringiensis observou-se maior ocorrência após a colheita do arroz $(47 \%)$, seguido da fase anterior ao preparo do solo $(40 \%)$ e pós-irrigação $(21 \%)$. Esse mesmo comportamento foi observado por GonzÁles et al. (2000), que detectaram a importância das raízes das plantas no aumento da sobrevivência dos esporos de $B$. thuringiensis, já que as raízes garantem proteção contra fatores negativos, bióticos e abióticos do solo. Por outro lado, B. cereus esteve mais frequente após irrigação do arroz (28\%), seguido da etapa da colheita (13\%) e da fase anterior ao preparo do solo (7\%). YÁñEZ e CABRIALES (2000) relatam que os esporos de $B$. cereus persistem nas folhas de plantas por períodos prolongados. $\mathrm{O}$ mesmo foi observado para $B$. sphaericus sendo mais representativo após a irrigação das áreas orizícolas $(18 \%)$, mas com baixa variação nas fases anterior ao preparo do solo (6\%) e pós-colheita $(4 \%)$. 
As bactérias agrupadas como Bacillus sp. tiveram maior ocorrência na fase anterior ao preparo do solo $(47 \%)$, mantendo equilíbrio durante as fases de pós- irrigação $(33 \%)$ e pós-colheita do $\operatorname{arroz}(36 \%)$.

Nesse contexto, os dados referentes às cepas de Bacillus spp., nos solos de cultivo de arroz irrigado nas diferentes fases da cultura, podem ter sido influenciados por fatores climáticos (Consoli et al., 1995). Outro fator a ser considerado é a aplicação de herbicidas, que foram utilizados no cultivo do arroz, uma vez que exercem influência sobre os microrganismos presentes no solo e sobre suas atividades, fator que pode inibir a população bacteriana no solo. As variações das frequências das bactérias esporulantes em cada fase do plantio podem ser observadas na tabela 4 e na figura 2 .

Comparou-se também a frequência das bactérias esporulantes em cada fase da cultura com a área controle, caracterizada por não ter qualquer tipo de tratamento. Os resultados revelaram que, durante a $2 .{ }^{a}$ coleta, houve uma variação significativa das bactérias entomopatogênicas, amostrando-se os dados das subáreas controle $(p<0,01)$. Dessa forma, os resultados revelam que a irrigação pode favorecer a variação na frequência de Bacillus spp. Essa variação pode ser observada principalmente no caso de $B$. sphaericus, uma vez que foi a fase de maior predomínio deste entomopatógeno, representando $71,4 \%$ do total de isolados constados durante a referida etapa da cultura (Tabela 5).

A prevalência de $B$. sphaericus após a irrigação, já havia sido abordada por Diss et al. (1999) na Região Sul do país, onde este bacilo foi encontrado mais frequentemente $(2,23 \%)$ que $B$. thuringiensis $(1,6 \%)$. Fuxa (1992) observou que cepas de $B$. sphaericus são capazes de permanecer viáveis no solo, mesmo após nove meses de sua liberação. Já a viabilidade de $B$. thuringiensis foi de oito semanas a quase três anos.

Em relação à comunidade microbiana no solo, Miorelli et al. (2005), constataram que a manutenção do solo em condições naturais e sem cultivo aumenta a atividade microbiana. Apesar disso, não é bem compreendida a variação da diversidade microbiana em agroecossistemas, uma vez que, em cada estação, pode ocorrer uma comunidade microbiana dominante acompanhada de outras menos abundantes, como visto nessa pesquisa. Essas variações podem estar associadas ao regime hídrico e também ao clima ou estações do ano em cada região, uma vez que a comunidade bacteriana do solo pode ser encontrada em maior número no verão, de acordo com Rogers e TATTER, 2001. Além disso, o teor e a qualidade dos resíduos vegetais constatados no solo, como a matéria orgânica, pode influenciar da mesma forma a comunidade bacteriana (ZILLI et al., 2003).

Tabela 4. Quantidade de isolados de Bacillus spp. obtidos em diferentes amostragens em três sistemas de cultivo de arroz irrigado

\begin{tabular}{|c|c|c|c|c|c|c|c|c|}
\hline Amostragens & B. thuringiensis & B. sphaericus & B. cereus & Bacillus sp. & Bacillus spp. & $\chi^{2}$ & $\mathrm{gl}$ & $\mathrm{p}$ \\
\hline $1 .^{\mathrm{a}}$ & 37 & 7 & 6 & 45 & 95 & - & - & - \\
\hline $2 .^{\mathrm{a}}$ & 25 & 34 & 21 & 39 & 119 & - & - & - \\
\hline $3 .^{\mathrm{a}}$ & 57 & 16 & 5 & 44 & 122 & - & - & - \\
\hline Total & 119 & 57 & 32 & 128 & 336 & 43.588 & 6 & $<0,01$ \\
\hline
\end{tabular}

$1 .^{\mathrm{a}}=$ antes de preparo do solo. $2 .^{\mathrm{a}}=$ após a irrigação. $3 \cdot^{\mathrm{a}}=$ após a colheita do arroz

Tabela 5. Frequência de Bacillus spp. nas subáreas controle durante a 2. ${ }^{a}$ fase, que corresponde à pós-irrigação da cultura

\begin{tabular}{lcccccc}
\hline & B. thuringiensis & B. cereus & B. sphaericus & \multicolumn{2}{c}{ Bacillus sp. } & Bacillus spp. \\
\hline C & 4 & 5 & 15 & 5 & 29 \\
\hline Total da fase & 25 & 34 & 21 & 39 & 119 \\
\hline
\end{tabular}

$\mathrm{C}=$ subáreas controle. 


\section{CONCLUSÕES}

1. Os dados correspondentes à frequência de bactérias entomopatogênicas pertencentes ao gênero Bacillus revelam a prevalência da espécie $B$. thuringiensis nos três sistemas de cultivo de arroz irrigado (SPC, SPD e SPG). Considerando as fases da cultura, $B$. thuringiensis teve sua maior ocorrência após a colheita do arroz (42 UFC), sendo a predominância de $B$. cereus após a irrigação da cultura (29 UFC), porém a espécie $B$. sphaericus ocorreu com baixa frequência nas três fases avaliadas. A presença de $B$. thuringiensis na fase de pós-colheita pode estar associada à ocorrência de insetos-praga durante o período de desenvolvimento da cultura, uma vez que essa bactéria é considerada uma das mais importantes espécies entomopatogênicas.

2. Assim, os resultados da presente pesquisa demonstram que as práticas agrícolas comumente utilizadas na cultura do arroz irrigado, nos sistemas de cultivo Convencional, Pré-germinado e Plantio direto, não causam impactos significativos na população de bacilos entomopatogênicos presentes no solo, especialmente $B$. thuringiensis, $B$. sphaericus e B. cereus.

\section{AGRADECIMENTOS}

Agradecemos a toda a equipe técnica do IRGA-EEA, pelo preparo da área experimental, auxílio nas coletas de solo e pela orientação fornecida durante a realização da pesquisa.

\section{REFERÊNCIAS}

AGOSTINETTO, D.; FLECK, N.G.; MENEZES, V. G. Herbicidas não seletivos aplicados na fase de maturação do arroz irrigado, Scientia Agrícola, v.58, p.277-285, 2001.

AZEVEDO, J.L. Biodiversidade Microbiana e Potencial Biotecnológico. In: MELO, I.S.; AZAVEDO, J.L. Ecologia Microbiana, Jaguariúna: EMBRAPA-CNPMA, 1998. p.445-461.

BOHNEN, H.; SILVA, L.S.; MACEDO, V.R.M.; MARCOLIN, E. 2005. Ácidos orgânicos na solução de um gleissolo sob diferentes sistemas de cultivo com arroz irrigado. Revista Brasileira de Ciência do Solo, v.29, p.475-480, 2005.

BROBOWSKI, V.L.; FIUZA, L.M.; PASQUALI, G.; BODANEZEZANETTINI, M.H. Genes de Bacillus thuringiensis: uma estratégia para conferir resistência a insetos em plantas. Ciência Rural, v.33, p.843-850, 2003.

CAPALBO, D.M.F.; VILAS-BÔAS, G.T.; ARANTES, O.M.N.; SUZUKI, M.T. Bacillus thuringiensis. Revista Biotecnologia Ciência e Desenvolvimento, v.34, p.69-85, 2005.
CASTRO, O.M.; PRADO, H.; SEVERO, A.C.R.; CARDOSO, E.J.B.N. Avaliação da atividade de microrganismos do solo em diferentes sistemas de manejo de soja. Scientia Agricola, v.50, p.212-219, 1993.

CHIN, K.J.; DITTMAR, H.; ULF, H.; WERNER L.; PETER H.J. Characterization and identification of numerically abundant culturable bacteria from the anoxic bulk soil of rice paddy microcosm. Applied and Environmental Microbiology Journal, v.65, p. 5042-5049, 1999.

CONSOLI, R.A.G.B.; CARVALHO-PINTO, C.J.; OLIVEIRA, M.A.;SANTOS, B.S.; LAMOUNIER, M.A; ALVES, R.S.A.;SILVA, C.M.B.; RABINOVITCH, L. Some environmental and biological factors influencing the activity of entomopathogenic Bacillus on mosquito larvae in Brazil. Memórias do Instituto Oswaldo Cruz, v.90, p. 121-124, 1995.

DIAS, S.C.; SAGARDOY, M.A.; SILVA, S.F.; DIAS, J.M.C.S. Characterization and pathogenic evaluation of Bacillus thuringiensis e Bacillus sphaericus isolates from Argentina soils. Biocontrol Journal, v.44, p.59-71, 1999.

FUXA, J.R. Impact $f$ the release of entomopathogens in the environment. Pesquisa Agropecuária Brasileira, v.27, p.349$369,1992$.

GIIL, S.S.; COWLES, E.A.; FRANCIS, V. Identification, isolation, and cloning of a Bacillus thuringiensis CryIAc Toxin-binding Protein from the midgut of the lepidopteran Insect Heliothis virescens. The Journal of Biological Chemistry, v.270, p.2727727282, 1995.

GONZÁLES, M.A.M.; OLIVERA, H.A.L.; CABRIALES, J.J.P.; YAÑES, J.M.S. Sobrevivencia de celulas vegetativas de Bacillus thuringiensis en la espermosfera/rizosfera de frijol. Revista Terra Latinoamericana, v.18, p.333-337, 2000.

HABIB, M.E.M.; ANDRADE, C.F.S. Bactérias entomopatogênicas. In: ALVES, S.B. Controle Microbiano de Insetos. São Paulo: FEALQ, 1998. p.383-446.

IRGA - INSTITUTO RIOGRANDENSE DO ARROZ. Arroz Irrigado: Recomendações Técnicas da Pesquisa para o Sul do Brasil. Santa Maria: SOSBAI, 2005. 159p.

MARCHEZAN, E.; SEGABINAZZI, T.; MARZARI, V.; VILLA, S.C.C.; AVILA, L.A. Manejo da adubação do arroz irrigado em sistema pré-germinado na produtividade e perda de nutrientes através da água de drenagem inicial. Ciência Rural, v.31, p. 877-879, 2001.

MARCHEZAN, E.; CAMARGO, E. R.; LOPES, S.I.G.; SANTOS, F.M.; MICHELON, S. Desempenho de genótipos de arroz irrigado cultivados no sistema pré-germinado com inundação contínua. Ciência Rural, v.34, p.1349-1354, 2004.

MIORELLI, D.; CASTILHOS, D.D.; GOMES, A. SILVA, PAULETTO, E.A. Biomassa e atividade microbiana de um planossolo sob diferentes sistemas de manejo. In: CONGRESSO DE INICIAÇÃO CIENTÍFICA E ENCONTRO DE PÓS-GRADUAÇÃO, 7., 2005, Pelotas. Anais... Pelotas: 2005. v.1, 4p. 
NETO, P.H.; BORGHI, E.; SVERZUT, C.B.; MANTOVANI, E.C.; GOMIDE, R.L.; NEWES, W.L.C. 2006. Análise multivariada da resistência do solo à penetração sob plantio direto. Ciência Rural, v.36, p.1186-1192, 2006.

PFÜLLER, E.E.; FRIES, M.R.; ANTONIOLLI, Z.I.; SANTOS, E.; PEREIRA, J.E.; CAMPOS, B.C.; SAMANIEGO, M.P.G. Dinâmica da população microbiana sob sistema de plantio direto e convencional. In: CONGRESSO FERTBIO, 2000, Santa Maria. Anais... Santa Maria: Fertbio. 2000. 4p.

POLANCZYK, R.A.; SILVA, R.F.P. da, FIUZA, L.M. Isolamento de Bacillus thuringiensis Berliner a partir de amostras de solos e sua patogenicidade para Spodoptera frugiperda (J.E.SMITH) (Lepidoptera: Noctuidae). Revista Brasileira Agrociência, v.10, p.209-214, 2004.

ROGERS, B.F.; TATE III, R.L. Temporal analysis of the soil microbial community along a toposequence in Pineland soils. Soil Biology and Biochemistry, v.33, p.1389-1401, 2001.

ROLF, D.A.; BENTZEN, P. The statistical analyses of mitocondrial DNA polymorphisms: $\chi^{2}$ and the problem of small samples. Molecular Biology and Evolution Journal, v.6, p.539-545, 1989.

SILVA, S.F.; DIAS, J.M.C. S; MONNERAT, R.G. Isolamento, identificação e caracterização entomopatogênica de bacilos de diferentes regiões do Brasil. Brasília: EMBRAPA Recursos Genéticos e Biotecnologia, 2002. 4p. (Comunicado Técnico, 70)

SOARES, J.L.; ESPÍNDOLA, C.R.; CASTRO, S.S. Alteração física e morfológica em solos cultivados sob sistema tradicional de manejo. Revista Brasileira de Ciência do Solo, v.29, p. 10051014, 2005.

SOUZA, R.O.; GOMES, A.S.; MARTINS, J.F.S.; PENA, Y.A. Densidade de semeadura e espaçamento entre linhas para arroz irrigado no sistema de plantio direto. Revista Brasileira de Agrociência, v.1, p.69-74, 1995.

TRAVERS, R.S.; MARTIN, P.A.W.; REICHELDERFER, C.F. Selective process for efficient isolation of soil Bacillus spp. Applied an Environmental Microbiology Journal, v.53, p.12631266, 1987.

WORLD ORGANIZATION. Informal consultation on the development of Bacillus sphaericus as microbial larvicide. Geneva: UNDP/World Bank/WHO Special programmer of research and training in tropical diseases, 1985. $24 \mathrm{p}$.

YÁÑEZ, J.M.S.; CABRIALES, J.J.P. Persistencia de esporas de Bacillus thuringiensis em hojas de maíz, de frijol y en el suelo. Revista Terra Latinoamericana, v.18, p. 325-331, 2000.

ZILLI, J.E.; RUMAJANEK, N.G; XAVIER, G.R.; COUTINHO, H.L; NEVES, M.C.P. Diversidade microbiana como indicador da qualidade do solo. Cadernos de Ciência \& Tecnologia, Brasília, v.20, p.391-411, 2003. 